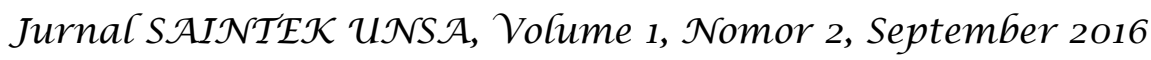

\title{
PENGARUH PENAMBAHAN SERBUK GERGAJI KAYU SENGON TERHADAP KUAT TEKAN DAN DAYA SERAP AIR PADA PAVING BLOCK
}

\author{
ZULKARNAEN $^{1}$, SRI MARIANI ${ }^{2}$ \\ Dosen Program Studi Teknik Sipil Fakultas Teknik Universitas Samawa Sumbawa Besar ${ }^{1}$ \\ Mahasiswa Program Studi Teknik Sipil Fakultas Teknik Universitas Samawa Sumbawa Besar ${ }^{2}$
}

\begin{abstract}
ABSTRAK
Penelitian ini bertujuan untuk mengetahu iApakah Ada Pengaruh Penambahan Serbuk Gergaji Kayu Sengon Terhadap Kuat Tekan Pada Paving Block Dan Seberapa Besar Daya Serap Air Pada Paving Block.

Penelitian ini menggunakan komposisi dengan perbandingan berat bahan susun paving block yang terdiri dari serbuk gergaji, semen Portland dan pasir dengan menggunakan campuran $1: 6$ dengan variasi takaran serbuk gergaji $0 \%, 5 \%, 10 \%, 15 \%$, dan $20 \%$.

Hasil penelitian yang dilakukan,bahwa penambahan serbuk gergaji kayu sengon (Albiziachinensis)dengan variasi campuran 5\%,10\%,15\%, dan 20\% gagal tidak dapat menghasilkan nilai kuat tekan pada paving block yang bisa disebabkan oleh penggunaan serbuk gergaji kayu sengon yang lolos ayakan 2,00 mm karena serbuk gergaji dengan ukuran tersebut terlalu besar untuk dijadikan sebagai bahan tambah dalam paving block sehingga terbentuk pori-pori yang besar pada benda uji serta kurangnya waktu pemeliharaan,sedangkan hasil kuat tekan 0\% serbuk gergaji didapat sebesar 120,04kg/ $\mathrm{cm}^{2}$ sesuai dengan (mutuDmenurut SNI-03-0691-1996).Berbeda dengan nilai daya serap airnya yang semakin meningkat seiring dengan bertambahnya persentase serbuk gergaji.

Hasil pengujian daya serap air paving block dengan komposisi 0\%, 5\%, 10\%, 15\%, dan 20\% serbuk gergaji masing-masing sebesar 7,94 \%, 25,73\%, 35,26\%, 38,06 \%, dan 47,95\%, sehingga persentase daya serap air yang sesuai dengan mutu III SNI 03-0691-1996yang kegunaannya untuk pejalan kaki dihasilkan pada benda uji 0\% serbuk gergaji, untuk benda uji dengan komposisi $5 \%$ - 20 \%serbuk gergaji hasilnya tidak sesuai dengan syarat yang telah ditentukan SNI 03-0691-1996.
\end{abstract}

Kata Kunci: Serbuk gergaji, Kuat tekan, Daya serap air

\section{PENDAHULUAN}

Laju pertumbuhan penduduk yang sangat tinggi berakibat pada tingginya kebutuhan akan sarana hunian. Pengembangan kawasan-kawasan hunian lebih lanjut akan memacu meningkatnya kebutuhan bahan bangunan. Bahan-bahan tersebut harus disediakan dalam jumlah besar dari alam maupun buatan. Salah satu cara untuk mengatasi permintaan kebutuhan bahan bangunan tersebut adalah dengan cara meningkatkan pemberdayaan sumber daya lokal yang berada di lingkungan kita.

Pemberdayaan sumber daya lokal dapat berupa pemanfaatan sampah maupun limbah. Pemanfaatan sampah maupun limbah disamping dapat mengurangi pencemaran lingkungan juga dapat digunakan sebagai alternatif pengganti bahan bangunan yang sudah ada. Salah satu sampah atau limbah

yang dapat dimanfaatkan dengan baik adalah limbah industri kayu.

PT.Global Sinergi Kayu Industri,yang terdapat dijalan Jurusan Samongkat KM 004 Desa Kerato Kecamatan Unter Iwes Kabupaten Sumbawa merupakan industri kayu yang bergerak dalam pengolahan kayu Sengon, salah satu komponen limbah dari industri ini adalah kayu yang tersisa akibat proses penggergajian yang menurut bentuknya berupa serbuk gergaji.Pada saat ini serbuk 
gergaji merupakan permasalahan aktual yang sering kali menjadi beban bagi industri perkayuan karena selain makan tempat juga kurang sedap dipandang dan hanya sebagian kecil yang dimanfaatkan.

Juga dapat meningkatkan nilai tambah dan nilai guna bahan sehingga dapat meningkatkan nilai ekonominya, menunjang pengadaan bahan dan sedikit banyak dapat mengatasi dampak negatif limbah industri kayu terhadap lingkungan.

Tidak ada bahan (material) yang ada di dunia ini yang tidak dapat dimanfaatkan. Setiap bahan pasti dapat dimanfaatkan asalkan sesuai dengan bidangnya. Berdasarkan hal tersebut, maka penelitimengajukan judul tentang, "Pengaruh Penambahan Serbuk Gergaji Kayu Sengon Terhadap Kuat Tekan Dan Daya Serap Air Pada Paving Block".

\section{METODOLOGI PENELITIAN}

Metodologi penelitian adalah suatu cara atau langkah yang ditempuh dalam memecahkan suatu persoalandengan mempelajari, mengumpulkan, mencatat dan menganalisa semua data-data yang diperoleh.

\section{Lokasi penelitian}

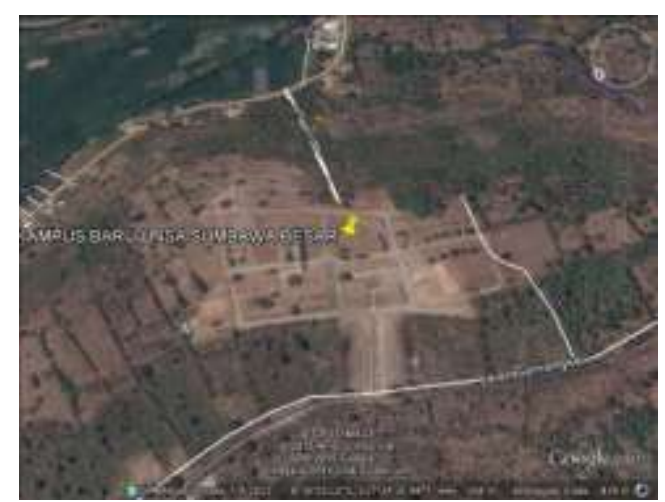

Gambar 1: Lokasi Penelitian

(sumber : Google earth 2016)

\section{Bahan Penelitian}

Bahan-bahan yang digunakan dalam penelitian ini adalah :

\section{Air}

Air yang digunakan dalam penelitian diambil dari jaringan air bersih dari Universitas Samawa.
Dengan memanfaatkan serbuk gergaji sebagai bahan isian pada paving block diharapkan diperoleh keuntungan dari bahan

\section{Semen}

Semen yang digunakan adalah semen portland type 1 (normal), merk Tiga Roda.

Pasir

Pasir yang digunakan dalam penelitian adalah pasir sungai dari Desa Kerekeh Kabupaten Sumbawa.

\section{Serbuk Gergaji}

Serbuk gergaji yang digunakan berasal dari industri kayu PT.Global Sinergi Kayulndustri yang terdapat dijalan Jurusan Samongkat KM.004 Desa Kerato Kecamatan Unter Iwes, Kabupaten Sumbawa.

\section{Alat Penelitian}

\section{Ayakan}

1. Ayakan No. 200 digunakan untuk pemeriksaan kandungan lumpur dalam pasir.

2.Ayakan dengan diameter berturut-turut $10 \mathrm{~mm}, 4,8 \mathrm{~mm}$, 2,4 mm, 1,2 mm, 0,6 mm, 0,3 $\mathrm{mm}, 0,15 \mathrm{~mm}$ yang dilengkapi dengan tutup dan alat penggetar (Sieve Shaker)digunakan untuk mengetahui gradasi pasir.
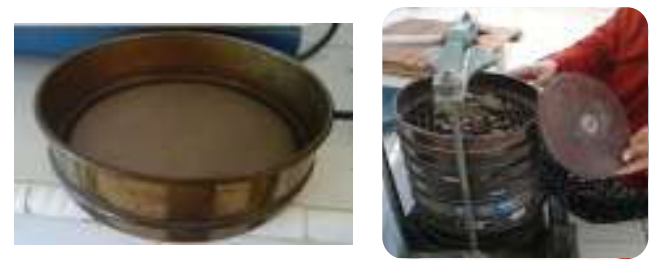

Gambar 2 : Ayakan (Sumber : Foto Pribadi 2016)

\section{Timbangan}

Timbangan digunakan untuk menimbang bahan susun adukan paving block. 


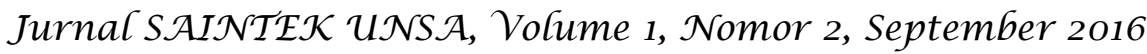

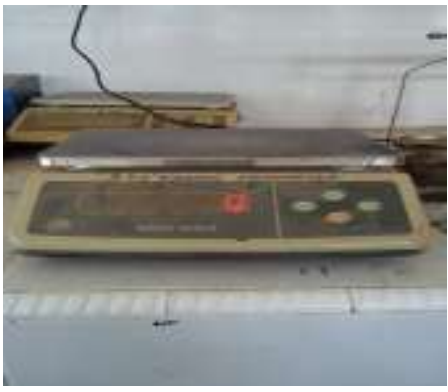

Gambar 3: Timbangan

(sumber : Foto Pribadi 2016)

\section{Picknometer}

Digunakan untuk mencari berat jenis pasir dengan kapasitas 500 gram.

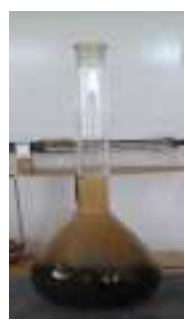

Gambar 4 : Picknometer (Sumber : Foto Pribadi 2016)

\section{Oven}

Oven, digunakan untuk memanaskan benda uji.

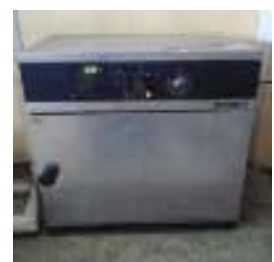

Gambar 5 : Oven

(Sumber : Foto Pribadi 2016)

\section{Sendok dan Mangkok}

Mangkok dan sendok, digunakan untuk menampung dan mengambil bahan-bahan yang akan di uji dan untuk mengaduk pasta mortar.

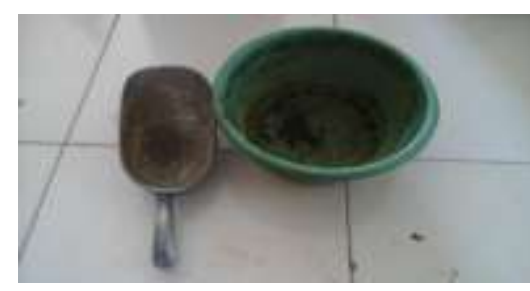

Gambar 6 : Sendok dan Mangkok (Sumber : Foto Pribadi 2016)

\section{Cetakan}

Cetakan digunakan untuk mencetak paving block.

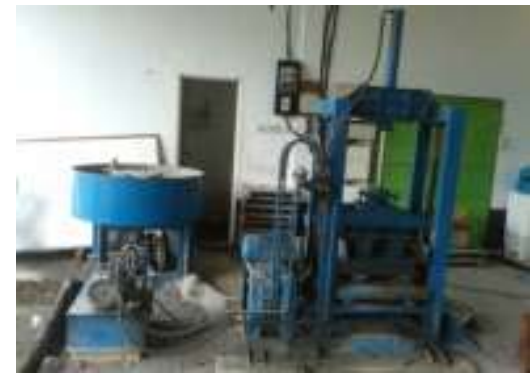

Gambar 7 : Cetakan

(Sumber : Foto pribadi 2016)

\section{Alat Uji Tekan}

Alat uji tekan yang digunakan adalah mesin uji CompressionTesting Machines dengan kapasitas kuat tekan 2000 kN, digunakan untuk pengujian kuat tekan Paving Block pada umur 7 hari. Pengujian dilakukan di Upt. Pengujian Bahan dan Peralatan Dinas Pekerjaan Umum KabupatenSumbawa.

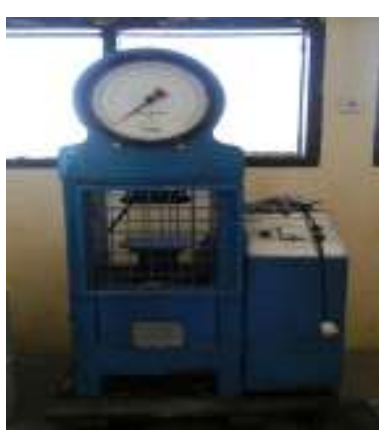

Gambar 8 : Alat Uji Tekan (Sumber : Foto Pribadi 2016)

\section{Kerucut Kronik}

Kerucut kronik digunakan untuk menentukan kondisi jenuh kering muka 
Jurnal SAIJ $\mathcal{N}$ EK UNS A, Volume 1, $\mathcal{N}$ omor 2, September 2016

(Saturated Surface Dry) dengan penumbuk berupa tongkat baja.

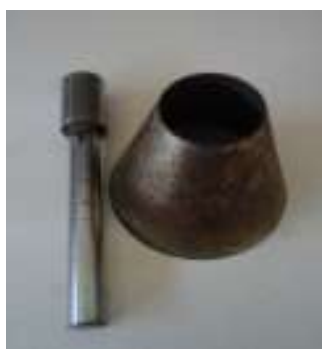

Gambar 9 : Kerucut Kronik

(Sumber : Foto Pribadi 2016)

\section{Bak Tempat Air}

Bak digunakan untuk

menampung air yang dibutuhkan dan juga untuk merendam serbuk gergaji.

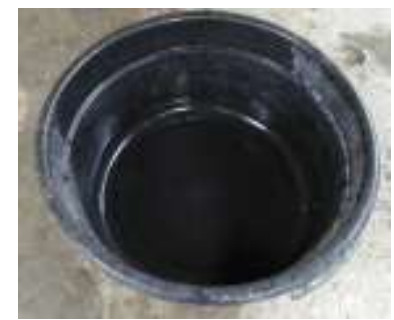

Gambar 10 : Bak Tempat Air

(Sumber : FotoPribadi 2016)

\section{Pemeriksaan Bahan}

\section{Pasir}

\section{a. Pemeriksaan Berat Jenis Pasir}

Langkah-langkah pemeriksaan berat jenis pasir adalah sebagai berikut :

- Pasir uji (SSD) dikeringkan dalam oven dengan suhu $110^{\circ} \mathrm{C}$ sampai beratnya tetap kemudian direndam di dalam air selama 24 jam.

- Setelah 24 jam air rendaman dibuang dengan hati-hati agar butiran pasir tidak ikut terbuang, tebarkan pasir dalam talam keringkan diudara panas dengan cara membolak-balikan pasir sampai kering.

- Pasir tersebut dimasukkan dalam piknometer sebanyak 500 gr $\left(\mathrm{W}_{1}\right)$ kemudian masukkan air dalam piknometer hingga mencapai $90 \%$ isi piknometer, putar dan gulinggulingkan piknometer sampai tidak terlihat gelembung udara didalamnya.

- Rendam piknometer dalam air dan ukur suhu air untuk penyesuaian perhitungan dengan suhu standar $25^{\circ} \mathrm{C}$.

- Piknometer berisi air dan pasir ditimbang dan dicatat beratnya $\left(W_{2}\right)$.

- Piknometer kosong dan berisi air ditimbang dan dicatat beratnya.

Berturut -turut $\left(W_{3}\right)$ dan $\left(W_{4}\right)$. Setelah mengendap pasir dikeluarkan dari piknometer tanpa ada yang tercecer, kemudian dikeringkan dalam oven selama 2 $x 24$ jam.

Berat jenis pasir ( $ү p s r)$ dihitung dengan rumus: $\quad W 1$

$$
\text { (W4 +W1-W2) }
$$

\section{b. Pemeriksaan Gradasi Pasir}

> Keringkan pasir dalam oven dengan suhu $110^{\circ} \mathrm{C}$ sampai beratnya tetap.

$>$ Keluarkan pasir dari oven didinginkan dalam desikator selama 3 jam.

$>$ Menyusun ayakan sesuai dengan urutannya, ukuran terbesar diletakkan di atas yaitu $4.8 \mathrm{~mm}, 2.4 \mathrm{~mm}, 1.2 \mathrm{~mm}, 0.6$ $\mathrm{mm}, 0.3 \mathrm{~mm}$ dan $0.15 \mathrm{~mm}$.

$>$ Memasukkan pasir dalam ayakan paling atas, tutup dan ayak dengan cara digetarkan selama 10 menit kemudian diamkan pasir selama 5 menit agar pasir tersebut mengendap.

$>$ Pasir yang tertinggal dalam masing-masing ayakan ditimbang beserta wadahnya.

> Gradasi pasir yang didapat dengan cara menghitung komulatif prosentase butir-butir 


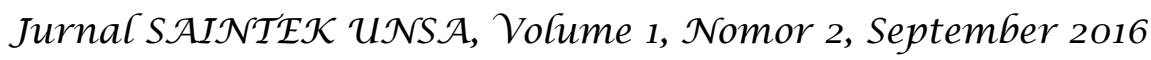

pasir yang lolos pada masingmasing ayakan. Nilai modulus halus pasir dihitung dengan menjumlahkan prosentase kumulatif butir yang tertinggal kemudian dibagi seratus.

\section{c. Pemeriksaan Kandungan Lumpur}

1) Mengambil contoh pasir yang lolos ayakan no. $200(0.075 \mathrm{~mm})$ telahkering oven selama 24 jam dengan suhu $110^{\circ} \mathrm{C}$, timbang beratnya kira-kira 100 gram $\left(W_{1}\right)$.

2) Mencuci pasir dengan air bersihyaitu dengan menuangkan pasir ke dalam gelas ukur yang berisi air yang mencapai 200 cc. Kemudian goyang-goyangkan (kocok) gelas ukur hingga air dan pasir tercampur, selanjutnya diamkan selama 1 menit dan air dibuang.

3) Percobaan ini diulang-ulang sampai air benar-benar jernih dan bersih.

4) Kemudian pasir di taruh di cawan dan dikeringkan dalam oven selama 24 jam selanjutnya ditimbang beratnya $\left(W_{2}\right)$.

Kadar lumpur pasir dapat dihitung dengan rumus:

$$
\frac{w_{1}-w_{2}}{w_{1}} \times 100 \%
$$

\section{d. Pemeriksaan Berat Isi Pasir}

1) Mold atau Selinder yang akan digunakan ditimbang dulu $\left(\mathrm{W}_{1}\right)$.

2) Contoh pasir dalam keadaan SSD dimasukkan kedalam silinder baja yang diketahui beratdan volumenya (V).

3) Silinder baja berisi pasir ditimbang dan dicatat beratnya $\left(\mathrm{W}_{2}\right)$.

Berat bobot isi dapat dihitung dengan rumus: $\underline{\mathrm{W} 2-\mathrm{W} 1}$

\section{e. Semen Portland}

Dalam penelitian ini, dilakukan dengan pemeriksaan visual. Semen diamati warna dan kehalusan butirnya, kemudian jika terdapat gumpalan maka gumpalan semen tersebut dihancurkan sehingga butirannya benar-benar halus.

\section{f. Air}

Pemeriksaan terhadap air dilakukan secara visual yaitu air harus bersih, tidak mengandung lumpur, minyak dan garam sesuai dengan persyaratan air untuk minum. Air yang digunakan dalam penelitian ini adalah air dari Universitas Samawa.

\section{g. Serbuk Gergaji}

Serbuk gergaji yang akan digunakan memerlukan pengolahan pendahuluan yang disebut proses mineralisasi. Proses ini diperlukan untuk mengurangi zat ekstratif seperti gula, tanin dan asam-asam organik dari tumbuh-tumbuhan agar daya lekatan dan pengerasan semen tidak terganggu. Proses ini dimulai dengan menghilangkan bagianbagian kasar serbuk gergaji kemudian dikeringkan lalu disaring dengan ayakan ukuran 2,0 $\mathrm{mm}$. Bagian serbuk gergaji yang lolos ayakan direndam dengan larutan kapur selama \pm 24 jam, ditiriskan sambil diangin-anginkan. Penggunaan larutan kapur dalam perendaman supaya serbuk gergaji membentuk kalsium karbonat yaitu sebagai zat perekat (tobermorite) sehingga serbuk gergaji membentuk massa yang kompak.

\section{Pembuatan Benda Uji ( Paving Block)}

Paving blockdapat diproduksi baik secara mekanis, semi mekanis, atau dengan cetak tangan. Pada umumnya paving blockyang diproduksi dengan peralatan 


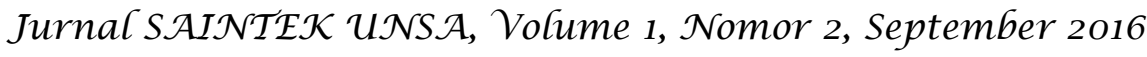

mekanis memiliki mutu yang lebihtinggi daripada dengan cara yang lainnya. Bahanbahan dicampur dalam perbandingan tertentu sesuai dengan peruntukan dan mutu yang direncanakan, kemudian dicetak dan dipadatkan dengan mesin pencetak, disimpan padatempat yang terlindung dari panas matahari langsung serta dari hembusan angin yang berlebihan.

Proses Pembuatan Paving Block Menyiapkan Bahan Susun Paving Block

a. Menimbang bahan-bahan susun paving block yaitu semen, pasir, bahan tambah (serbuk gergaji) dan air dengan berat yang telah ditentukan dalam perencanaan campuran paving block.

b. Mempersiapkan cetakan paving block dan peralatan lain yang dibutuhkan.

Tabel 1 : Rencana adukan paving block $21 \times 10,5 \times 7 \mathrm{~cm}$.

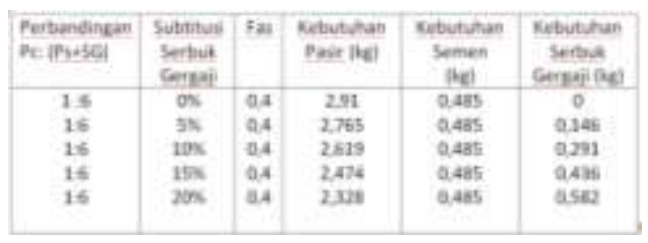

Rencana benda uji yang akan di buat dalam penelitian ini adalah sebanyak 3 buah benda uji,dari masing-masing subtitusi serbuk gergaji $0 \%$, 5\%, 10\%, $15 \%$, dan $20 \%$ dan untuk rencana kebutuhan satu benda uji, telah ditentukan pada tabel 1.

Pengadukan Campuran Paving Block

a. Mencampurkan semua bahan pengisi (agregat halus), bahan ikat (semen), dan bahan tambah (serbuk gergaji), dalam komposisi yang telah ditentukan.

b. Memasukkan air sebesar $80 \%$ dari jumlah air yang dibutuhkan dengan fas 0,4 dan bahan-bahan campuran yang telah dibuat. c. Pengadukan dilakukan sebanyak satukali untuk setiap macam campuran dan setiap pengadukan dilakukan pemeriksaan.

\section{Pencetakan Paving Block}

a. Adukan bahan paving block dimasukkan kedalam cetakan paving block yang sebelumnya pada bagian dalam cetakan diberi minyak pelumas.

b. Isi cetakan dengan adukan paving block sampai keadaan munjung lalu dipadatkan dengan pemukul dan sesuai dengan variabel penelitian.

c. Permukaan paving block harus benar-benar dalam keadaan rata pada bagian atas cetakan.

d. Buka cetakan dan tempatkan paving block pada tempat yang sejuk, tidak terkena matahari secara langsung.

\section{Perawatan}

Setelah benda uji selesai dicetak, tempatkan pada tempat yang teduh selama beberapa hari dengan tiap pagi disiram air secukupnya. Setelah 5 hari ambil benda uji dari landasan cetak, susun yang rapi sampai benda uji berumur 7 hari untuk dilakukan pengujian.

\section{Tahap Pelaksanaan Pengujian} Pengujian Kuat Tekan Paving Block

a. Masing-masing benda uji ( paving block ) diukur panjang, lebar, tinggi, dan beratnya.

b. Meletakkan benda uji pada mesin tekan secara simetris.

c. Menjalankan mesin tekan dengan penambahan beban yang konstan berkisar antara 2 sampai $4 \mathrm{~kg} / \mathrm{cm}^{2}$ per detik.

d. Melakukan pembebanan hingga benda uji hancur dan mencatat beban maksimum yang terjadi selama pengujian. 


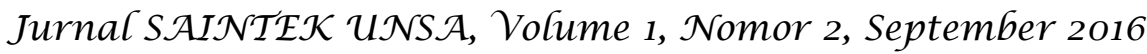

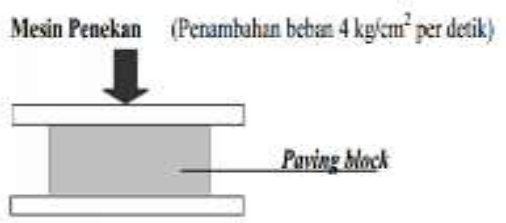

Gambar 11 : Pengujian kuat tekan paving block

Pengujian Daya Serap Air PavingBlock

a. Paving blockyang telah berumur 7 hari dan dalam kondisi kering udara dimasukkan dalam oven dengan suhu $110^{\circ}$ selama 24 jam.

b. Setelah 24 jam Paving blockdikeluarkan dan didinginkan.

c. Paving blockkering oven diitmbang bertanya $\left(\mathrm{W}_{1}\right)$.

d. Rendam paving blockselama 24 jam, setelah itu diangkat dan ditimbang beratnya $\left(W_{2}\right)$.

Analisa Data

Berat Jenis Pasir

Berat jenis pasir $(\gamma p s r)=w_{1}$

$$
\left(W_{4}+W_{1}-W_{2}\right)
$$

Ket erangan :

$W_{1}=$ Berat pasir dalam keadaan kering permukaan (gram)

$W_{2}=$ Berat piknometer berisi pasir dan air (gram)

$W_{3}=$ Berat pasir setelah kering oven (gram)

$W_{4}=$ Berat piknometer berisi air (gram)

Kandungan Lumpur Pasir

Kandungan lumpur $=\frac{W_{1}-W_{2}}{W_{1}} \times 100 \%$

Keterangan :

$W_{1}=$ Berat pasir kering oven (gram)

$W_{2}=$ Berat pasir kering setelah di cuci (gram)

Berat Isi Pasir

$$
W_{2}-W_{1}
$$

Berat isi pasir $=$
Keterangan :

$$
W_{1}=\text { Berat mold (gram) }
$$

$W_{2}=$ Berat mold berisi pasir (gram)

$V=$ Volume mold (gram)

\section{Kuat Tekan Paving Block}

$$
f c=\frac{P}{A}
$$

Keterangan :

$f c=$ Kuat tekan paving block $\left(\mathrm{kg} / \mathrm{cm}^{2}\right)$

$P=$ Beban maksimum $(\mathrm{kg})$

$A=$ Luas penampang Paving Block $\left(\mathrm{cm}^{2}\right)$

Daya Serap Air Paving Block

$$
\text { Porositas }=\frac{W_{2}-W_{1}}{W_{1}} \times 100 \%
$$

Keterangan :

$$
\begin{aligned}
W_{1}= & \text { Berat Paving Block dalam } \\
& \text { keadaankering mutlak } \\
& \text { (dioven) }(\mathrm{kg}) \\
W_{2}= & \text { Berat Paving Block } \\
& \text { setelah direndam }(\mathrm{kg})
\end{aligned}
$$

\section{Bagan Alir Penelitian}

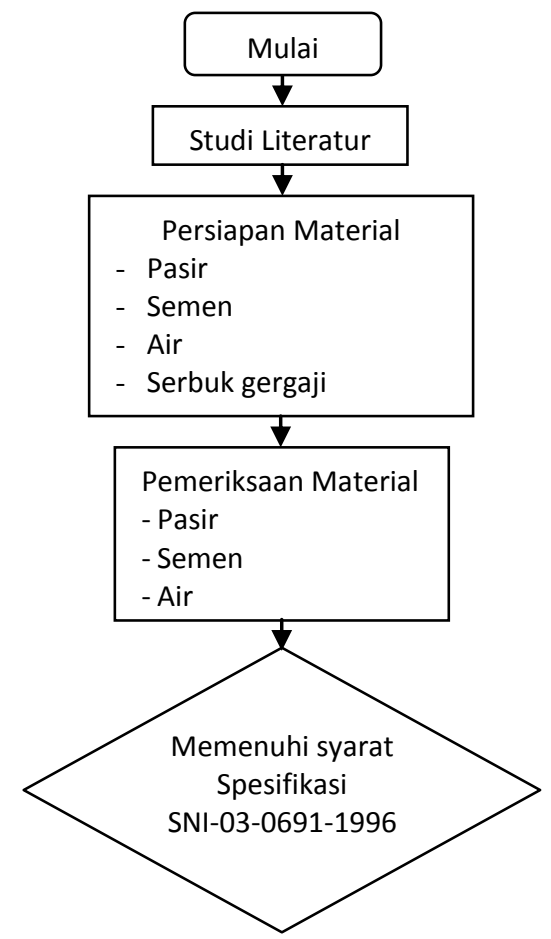




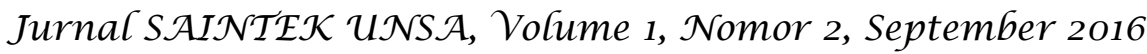

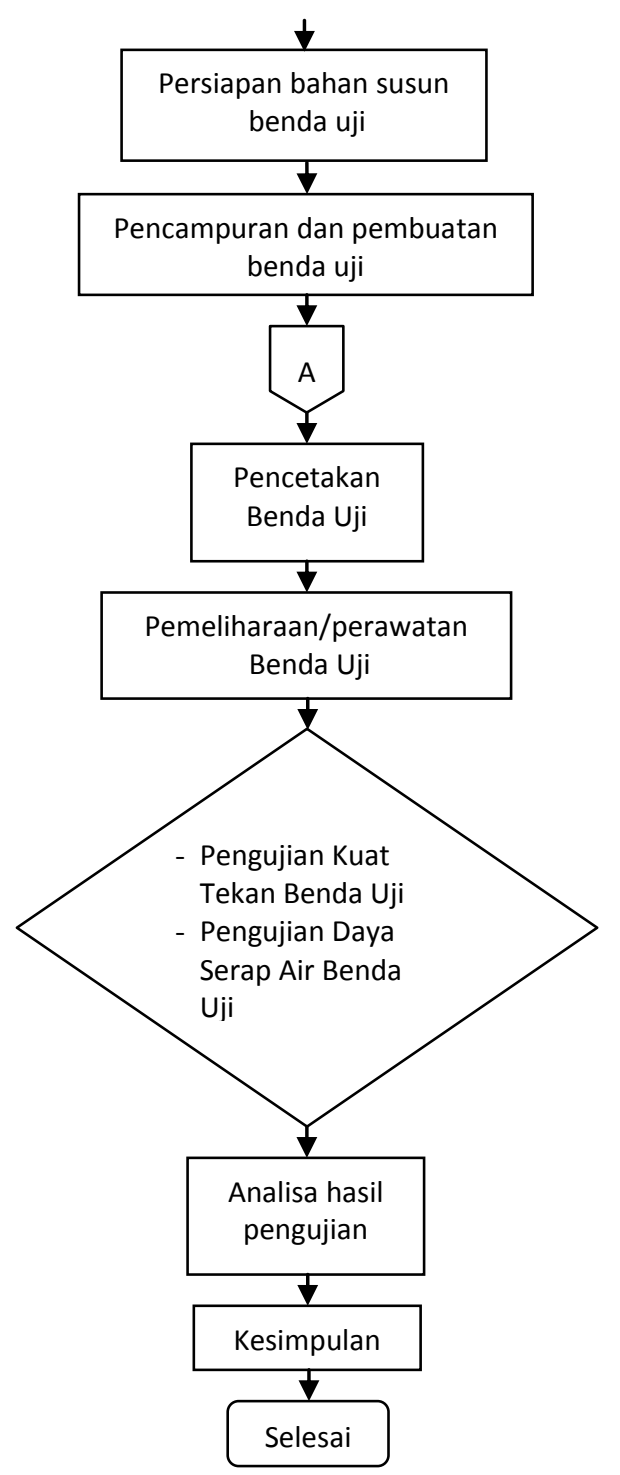

HASIL DAN PEMBAHASAN

Hasil Pemeriksaan Bahan Susun Paving Block

\section{Air}

Hasil pemeriksaan menunjukkan bahwa air dari Universitas Samawa Kabupaten Sumbawa dalam kondisi jernih tidak berwarna dan tidak berbau.

\section{Semen Portland}

Semen Portland yang digunakan saat penelitian tidak menggumpal dan dalam keadaan kering sehingga semen layak digunakan sebagai bahan penelitian.

Agregat halus (pasir)

Pasir yang digunakan dalam penelitian ini adalah, pasir sungai dari Desa Kerekeh. Secara umum mutu pasir tersebut memenuhi syarat untuk dapat digunakan sebagai bahan bangunan, walaupun demikian perlu diadakan pemeriksaan mengenai setiap mutu pasir yang akan digunakan dalam penelitian dan untuk pemeriksaan mutu pasir tersebut dilaksanakn di Upt. Pengujian Bahan dan Peralatan Dinas Pekerjaan Umum Kabupaten Sumbawa. Berikut ini adalah hasil pemeriksaan yang dilakukan :

\section{a. Gradasi Pasir}

Hasil pemeriksaan pasir menunjukkan bahwa modulus kehalusan pasir adalah 2.25 sehingga telah memenuhi syarat yang ditetapkan SNI 03-6821-2002 (2002 :172) yakni dengan modulus halus 2.0 sampai 3.0 dan pasir masuk dalam kategori sebagai pasir adukan/mortar.

b. Berat jenis pasir

Pemeriksaan menunjukkan bahwa berat jenis pasir dalam keadaan SSD adalah 2.51. Berat jenis pasir secara umum berkisar antara 2.50 sampai dengan 2.70. Beton yang dihasilkan beberat jenis sekitar 2.3 dengan kuat tekan 15-40 $\mathrm{MPa}$, betonnya pun disebut beton normal (Tjokrodimulyo, 1996), jadi pasir yang diperiksa tersebut masih memenuhi syarat sebagai bahan susun beton atupun paving block.

\section{c. Kandungan Lumpur}

Berdasarkan hasil pemeriksaan yang dilakukan kadar lumpur pasir yang digunakan dalam penelitian ini adalah $3.205 \%$ sehingga pasir memenuhi syarat untuk digunakan sebagai bahan bangunan karena menurut SNI 03-6821-2002 (2002 :172) kadar lumpur maksimum yang diijinkan adalah 5\%. Untuk tabel hasil kandungan lumpur dapat dilihat pada lampiran 2. 
Jurnal SAIN $\mathcal{A}$ EK UNNSA, Volume 1, Nomor 2, September 2016

\section{d. Berat Isi Pasir}

Penelitian berat isi pasir terhadap pasir Krekeh yang dilakukan di Upt.Dinas Pekerjaan Umum diperoleh hasil yaitu besarnya berat satuan pasir Kerekeh yang dilakukan tanpa tumbukan atau tanpa pemadatan sebesar 1.51 $\mathrm{kg} / \mathrm{m}^{3}$.

\section{Hasil Uji dan Pembahasan Kuat Tekan} Paving Block

Pengujian kuat tekan dilakukan setelah benda uji berumur 7 hari, setelah dilakukan perawatan dengan cara ditempatkan pada tempatyang teduh dan dilakukan penyiraman pada waktu pagi hari selama 3 hari.Benda uji $0 \%$ serbuk gergaji dengan perbandingan 1:6 menghasilkan kuat tekan sebesar $120 \mathrm{~kg} / \mathrm{cm}^{2}$ sesuai dengan mutu D menurut SNI 03-06911996 sedangkan benda uji 5\% - 20\% tidak menghasilkan nilai kuat tekan.

Adapun penyebab kurangnya kualitas paving block dikarenakan Serbuk gergaji merupakan butiran-butiran kayu yang memiliki sifat-sifat kimia (selulosa, hemiselulosa, lignin dan zat ekstraktif kayu) sehingga satu butir serbuk gergaji merupakan kumpulan sel-sel kayu dinding sel dibentuk oleh selulosa yang disatukan oleh zat perekat lignin yang mempunyai kekuatan yang relatif lemah jika

dibandingkan dengan selulosa, sehingga serbuk gergaji merupakan bahan yang terdiri dari partikelpertikel kuat tetapi tidak terikat dengan kuat. Selain itu serbuk gergaji juga memiliki bentuk dan tekstur permukaan butir-butir yang belum terdefinisikan dengan jelas, sehingga sifat-sifat tersebut sulit diukur dengan baik dan pengaruhnya terhadap kekuatan paving block sulit diperiksa dengan teliti.

Faktor terbesar yang mengakibatkan penurunan kekuatan paving block adalah sifat kimia kayu yaitu kandungan zat ekstraktif pada serbuk gergaji. Kandungan ekstraktif yang tinggi akan menghambat proses hidrasi semen yang mengakibatkan penurunan kekuatan pasta semen dan memperlemah lekatan antara butir agregat halus dan pasta semen, sehingga dengan semakin tingginya kandungan serbuk gergaji maka semakin tinggi pula kandungan zat ekstraktif dalam campuran yang akan menyebabkan terjadinya penurunan kekuatan paving block.

Tabel 2 : Hasil uji kuat tekan paving block

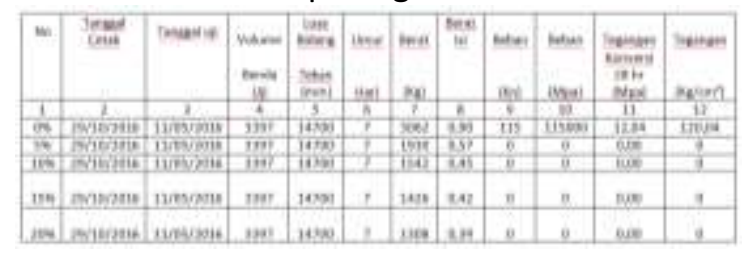

\section{Hasil Uji dan Pembahasan Daya Serap} Air Paving Block

Pengujian daya serap air dilakukan setelah benda uji berumur 7 haridengan membandingkan berat basah dan kering oven.

Tabel 3 : hasilpengujian daya serap air paving block

\begin{tabular}{||c|c|c|c||}
\hline $\begin{array}{c}\text { Persen } \\
\text { Serbuk } \\
\text { Gergaji }\end{array}$ & $\begin{array}{c}\text { Berat } \\
\text { Kering } \\
\text { Oven } \\
\text { (gram) }\end{array}$ & $\begin{array}{c}\text { Berat } \\
\text { Terendam Air }\end{array}$ & $\begin{array}{c}\text { Daya } \\
\text { Serap } \\
\text { Air }\end{array}$ \\
\hline & & & \\
\hline $0 \%$ & 1990 & 2148 & 7,94 \\
$5 \%$ & 412 & 518 & 25,73 \\
$10 \%$ & 312 & 422 & 35,26 \\
$15 \%$ & 310 & 428 & 38,06 \\
$20 \%$ & 292 & 432 & 47,95 \\
\hline
\end{tabular}

Grafik hasil pengujian daya serap paving block dapat dilihat pada (gambar 12) dibawah ini. 


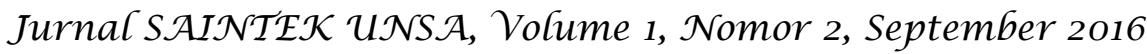

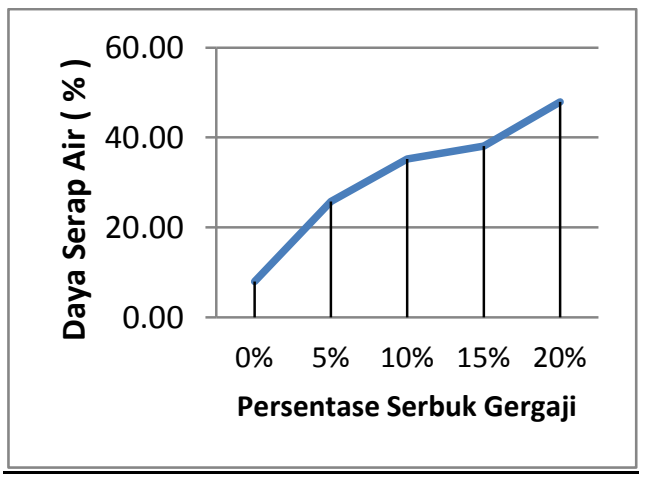

Gambar 12 : Grafik daya serap air paving block

Dari hasil pengujian daya serap air (gambar 4.1) terlihat terjadinya peningkatan daya serap paving block dari $5 \%$ serbuk gergaji sebesar $25,73 \%$; $10 \%$ serbuk gergaji sebesar $35,26 \% ; 15 \%$ serbuk gergaji sebesar $38,06 \%$; dan $20 \%$ serbuk gergaji sebesar47,95 \%. Dari grafik persentase serbuk gergaji pada gambar 4.1 dapat dilihat bahwa daya serap airpaving block semakin meningkat dengan bertambahnya kandunganserbuk gergaji dalam campuran.

Kecenderungan daya serap paving block disebabkan karena serbuk gergaji yang bersifat higroskopis atau menyerap air. Sifat higroskopis serbuk gergaji akan memberikan kontribusi yang besar terhadap kenaikan daya serap air paving block. Serbuk gergaji dapat dikatakan sebagai bahan yang berpori, sehingga air dapat dengan mudah terserap dan mengisi pori-pori tersebut.

\section{KESIMPULAN}

Dari hasil penelitian dan pembahasan Pengaruh Penambahan Serbuk Gergaji Kayu Sengon Terhadap Kuat Tekan dan Daya Serap Air Pada Paving Block dapat disimpulkan sebagai berikut :

1. Ada pengaruh penambahan serbuk gergaji kayu sengon terhadap kuat tekan pada pavingblock. Hal ini ditunjukkan tidak adanya nilai kuat tekan pavingblock dengan bertambahnya serbuk gergaji kayu sengon yang lolos ayakan 2,00 mmdenganmenggunakancampuran 1 : 6 dengan variasi campran $5 \%, 10 \%, 15 \%$ dan $20 \%$ serta kurangnya waktu pemeliharaan, sehinnga penelitian ini gagal untuk mencapai nilai kuat tekan pada variasi penambahan serbuk gergaji yang telah ditentukan.Kuat tekan paving block yang dihasilkan pada campuran serbuk gergaji0\% dengan campuran 1 : 6 sebesar 120,04 kg/ $\mathrm{cm}^{2}$, tergolong dalam mutu $D$ sesuai denganSNI-030691-1996 dengan rata-rata kuat tekan sebesar $100 \mathrm{~kg} / \mathrm{cm}^{2}$.

2. Paving block dengan variasi serbuk gergaji $5 \%$ sampai $20 \%$ mengalami kenaikanpada daya serap airnya sebesar $25,73 \%$ sampai $47,95 \%$. Hal ini dikarenakan sifat serbuk gergaji yang higroskopis atau mudahmenyerap air. Berdasarkan hasil penelitian ini maka limbah serbuk gergaji kayu sengon dari PT. Global Sinergi Kayu Industri, yang terdapat dijalan Jurusan Samongkat KM 004 Desa Kerato Unter Iwes Kabupaten Sumbawa, tidak dapat digunakansebagai bahan campuran dalam pembuatan paving block dengan perbandingan $1: 6$ karena nilai kuat tekan dan daya serap airnyatidak memenuhi syarat $\mathrm{SNI}-03-$ 0691-1996.

\section{SARAN}

1. Perlu adanya penelitian lebih lanjut mengenai penggunaan serbuk gergaji kayu sengon sebagai bahan campuran pembuatan paving block. Adanya penelitian lanjutantersebut adalah penggunaan cetakan hidrolis yang telah terukur bebannyapada saat pencetakan, penggunaan variasi nilai fas, perbandinganjumlah semen dengan agregat agar diperoleh kuat tekan yang baik serta menggunakan serbuk gergaji yang lolos ayakan lebih halus dari 2,00 atau $1,00 \mathrm{~mm}$. 


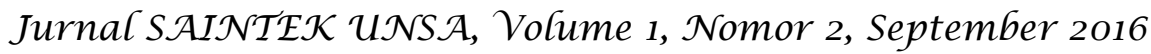

2. Melihat kandungan kimia serbuk gergaji yang sebagian besar terdiri dariselulosa, dimana menuntut pengolahan terlebih dahulu serta mempunyaisifat higroskopis maka perlu dilakukan penelitian lebih lanjut mengenaipengaruh penggunaan serbuk gergaji ditinjau dari waktu pemeliharaan.

\section{DAFTAR PUSTAKA}

Ahmad Rosman, 2007. Bahan Bangunan Sebagai Dasar Pengetahuan. Jakarta: Banguncipta Pustaka.

Anonim, 1985. Persyaratan Umum Bahan Bangunan Indonesia 1982 (PUBI1982). Bandung: Pusat Penelitian dan Pengembangan Pemukiman. Balitbang Departemen Pekerjaan Umum.

Anonim, 2002, Standar Nasional Indonesia, SK SNI 03 - 6821 - 2002, Jakarta: Departemen Pekerjaan Umum.

Anonim, 2006. Modul Pemanfaatan Agregat Halus (pasir)untuk Komponen Bangunan.www.BahanBangunan. http://khedanta.files.wordpress.com/ 2011/05/3.png. (Diakses pada tanggal 01 April 2016).

Anonim, 2015. Sengon http://id.wikipedia.org/wiki/Berkas:Al bizia-chinensis-bark.jpg. (Diakses pada tanggal 27 Mei 2016).

Daryanto, 2009. Pengetahuan Teknik Bangunan. Jakarta: Rineka Cipta.

Kusuma Dwi, 2012. Paving Block. http://dwikusumadpu.wordpress.com 2012/12/27/paving-block. (Diakses pada tanggal 24 April 2016).

Kusuma dwi, 2013. Pembuatan paving block dengan kualitas baik. http://dwikusumadpu.wordpress.com 2013/03/10/pembuatan-pavingdengan-kualitas-baik/bahanpembuatan-paving/. (Diakses pada tanggal 24 April 2016).

Mulyono Tri, 2004. Teknologi Beton. Yogyakarta: Andi.
Nugraha Paul, Antoni, 2007. Teknologi Beton dari Material, Pembuatan, ke Beton Kinerja Tinggi. Yogyakarta: Andi.

Nurmawati Ida, 2006. Pemanfaatan limbah industri Penggergajian kayu sebagai bahan Subtitusi pembuatan paving block. Skripsi, Jurusan Teknik Sipil, Fakultas Teknik, Universitas Negeri Semarang (UNNES).

Purnama, A, 2011. STUDI KELAYAKAN PEMBANGUNAN PEMBANGKIT LISTRIK TENAGA MIKROHIDRO Studi Kasus: PLTMH Minggir pada saluran irigasi Minggir di Padukuhan Klagaran Desa Sendangrejo Kecamatan Minggir Kabupaten Sleman, Jurnal Unsa Progress. Vol.10, No.15, Oktober, Universitas Samawa, Sumbawa Besar. 